\title{
O PROCESSO DE INDUSTRIALIZAÇÃO BAIANO E SEUS IMPACTOS DEMOGRÁFICOS E OCUPACIONAIS NO MUNICÍPIO DE FEIRA DE SANTANA-BA
}

\author{
Gesner Brehmer de Araújo Silva \\ Universidade Estadual de Feira de Santana (UEFS) \\ gesnerbrehmer@hotmail.com \\ José Raimundo Oliveira Lima \\ Universidade Estadual de Feira de Santana (UEFS) \\ zeraimundo@uefs.br
}

\begin{abstract}
RESUMO
Iniciado formalmente nos anos 1950, com a instalação do Centro Industrial do Aratu em Salvador, o processo de industrialização do estado da Bahia trouxe profundas transformações tanto na estrutura produtiva, quanto econômica no estado. Feira de Santana, como segunda maior cidade do estado, não passou inócua a esse processo com a instalação do Centro Industrial do Subaé (CIS) na década de 1970. O propósito deste artigo é de analisar os impactos desse processo de industrialização no município de Feira de Santana sobre duas óticas: a demográfica e a ocupacional, através de dados disponíveis no Instituto Brasileiro de Geografia e Estatística (IBGE). Como resultados obtidos, inferiu-se que após o processo de industrialização baiano e a instalação do CIS, houve uma mudança demográfica no município, que passou a concentrar maior população urbana e ocupacional que, por sua vez, passou a ser absorvida pelos setores da indústria e de serviços.
\end{abstract}

Palavras-chave: Industrialização baiana. Impactos demográficos em Feira de Santana. Impactos ocupacionais em Feira de Santana.

\section{THE BAHIAN INDUSTRIALIZATION PROCESS AND ITS DEMOGRAPHIC AND OCCUPATIONAL IMPACTS IN THE MUNICIPALITY OF FAIR DE SANTANA-BA}

\begin{abstract}
Formally started in the 1950s, with the installation of the Aratu Industrial Center in Salvador, the process of industrialization in the state of Bahia brought profound transformations both in the productive and economic structures in the state. Feira de Santana, as the second largest city in the state, did not pass this process harmlessly with the installation of the Subaé Industrial Center (CIS) in the 1970s. The purpose of this article is to analyze the impacts of this industrialization process in the municipality of Feira de Santana on two perspectives: demographic and occupational, through data available at the Brazilian Institute of Geography and Statistics (IBGE). As results obtained, it was inferred that after the Bahian industrialization process and the installation of the CIS, there was a demographic change in the municipality, which started to concentrate a larger urban and occupational population, which, in turn, started to be absorbed by the industry sectors. and services.
\end{abstract}

Keywords: Bahian industrialization. Demographic impacts in Feira de Santana. Occupational impacts in Feira de Santana.

\section{INTRODUÇÃO}

Como argumentam Guerra e Teixeira (2002) e Cavalcante (2008), a Bahia, no início dos anos 1960, coloca em prática uma política de desenvolvimento industrial através de um processo de intervenções 
estatais planejadas, sobretudo na Região Metropolitana de Salvador (RMS), através da oferta de terrenos dotados de infraestrutura e incentivos fiscais, entre outras ações. Segundo Pessoti (2008), essa política foi responsável por uma média de crescimento anual de $7 \%$ do Produto Interno Bruto (PIB) do estado, entre as décadas de 1960 e 1970, ancorado, principalmente, pelo Centro Industrial de Aratu e o Complexo Petroquímico de Camaçari, ambos no estado da Bahia.

Para Pessoti e Pessoti (2010), os anos de 1970 podem ser entendidos como a década que consolida de vez o processo de industrialização iniciado nos anos 1950, sobretudo após a implantação do Complexo Petroquímico de Camaçari (COPEC). É a partir de então que o ambiente industrial baiano passa a dar mais atenção ao setor secundário, colocando-o em condições mais favoráveis.

De acordo com Guerra e Teixeira (2000), a industrialização baiana foi direcionada aos setores químicos e petroquímicos devidos a três motivos: i) O estado da Bahia era na época o maior produtor de petróleo do país e já possuía uma refinaria (Landulfo Alves). Tinha-se assim uma base técnica para a implantação do polo petroquímico; ii) nos primeiros anos da década de 1970 havia carência na produção nacional de alguns insumos básicos usados pela indústria de transformação do Sudeste e do Sul; iii) o Governo Federal tinha, entre seus objetivos, a diminuição dos desequilíbrios regionais. Dado esse contexto, diversos empreendimentos foram implantados, destacando-se os realizados no COPEC. Com o passar do tempo, sua consolidação fez com que a participação relativa do setor primário no PIB Setorial Baiano diminuísse de 40\%, em 1960, para $16,4 \%$ em 1980. O setor secundário, por sua vez, no mesmo período, quase triplica sua participação, saltando de $12 \%$ para $31,6 \%$, colocando a economia baiana numa nova posição.

Nesse contexto, observa-se que no início da década de 1970, influenciado pelos ideais da Superintendência do Desenvolvimento do Nordeste (SUDENE), há uma tentativa, por parte do governo do Estado, de especializar e interiorizar o desenvolvimento industrial da Bahia por meio de metas que visavam estabelecer mudanças na estrutura produtiva, tendo como principal objetivo dinamizar os municípios do interior da Bahia, integrando-os à matriz produtiva do estado. Em busca de concretizar esse objetivo, foram implementados, em sua concepção original, distritos industriais nos municípios de llhéus, Jequié, Vitória da Conquista e Juazeiro, cujas áreas eram admitidas como estratégicas pelo Governo do Estado, seguindo a lógica estratégica de desconcentração concentrada ${ }^{1}$ pautada em empreendimentos industriais em locais escolhidos em função da possibilidade de efeitos de transbordamento para os municípios situados na circunvizinhança dos distritos industriais (SOUTO et al., 2017, p. 02).

Em razão disso, consolida-se na Bahia, na década de 1970, a estrutura industrial de perfil complementar às indústrias do Centro-Sul, centrada basicamente na produção de bens intermediários, principalmente da indústria petroquímica. A essa concentração setorial une-se a concentração espacial, caracterizando fortemente o novo perfil econômico do estado. Em decorrência das externalidades ${ }^{2}$ e das economias de aglomeração ${ }^{3}$ geradas pelas indústrias e infraestrutura já instaladas na RMS, fatores como logística, serviços de apoio e manutenção e a proximidade com fornecedores aumentaram o poder de atração dessa mesma região, em especial para as indústrias dinâmicas, mais modernas e tecnologicamente mais sofisticadas. Nesse universo, temos as indústrias dos ramos dos produtos químicos, plásticos, farmacêuticos e veterinários (MASCARENHAS, 2001).

Em suma, todo o conjunto de empreendimentos iniciados pela construção da Refinaria Landulfo Alves, na década de 1950, até a implantação do Polo Petroquímico de Camaçari, nos anos 1970, serviu para a consolidação da industrialização baiana, alterando de forma significativa e definitiva a estrutura econômica, social e política do estado ao mudar de uma vez por todas o peso do PIB estadual com redução significativa da agricultura e com crescimento constante da participação do

\footnotetext{
1 Processo de maior democratização do espaço industrial do país, mas que acabou por se concentrar apenas em cidades específicas.

2 Conceito econômico referente a quando alguma empresa ou indústria executa uma ação que gera efeitos positivos ou negativos que vão além de seu cliente ou consumidor final, ou seja, a pessoas terceiras a sociedade.

${ }^{3}$ Etapa de um processo de industrialização onde empresas se concentram em uma determinada região do espaço geográfico. 
setor secundário, com destaque para os setores químico, petroquímico, metalúrgico, siderúrgico e extrativo mineral, cravando de vez a posição da Bahia como uma das principais fornecedoras nacionais de bens intermediários (NÓVOA, 1979).

Para Almeida (2009), em 1970 através da elaboração do Plano Diretor do Centro Industrial do Subaé (PDCIS), Feira de Santana começa a estabelecer a criação do Distrito Industrial do Subaé com o objetivo de estimular a expansão deste município como polo secundário e auxiliar da Bahia de modo a funcionar como complemento do eixo industrial que já havia se estabelecido na Região Metropolitana de Salvador (RMS). Características marcantes como sua privilegiada localização rodoviária, a já existência de um pequeno parque industrial, a instalação do Centro de Desenvolvimento Industrial (CEDIN) e os incentivos fiscais para as indústrias de bens de consumo final foram decisivas na tentativa de promoção de um crescimento econômico local por parte do Distrito Industrial do Subaé. A instalação deste distrito industrial em Feira de Santana promoveu uma mudança na configuração socioeconômica e populacional da cidade, dando a ela características mais urbanas (maior infraestrutura urbana e concentração populacional na cidade).

Segundo Cruz (1999), o crescimento da indústria local na década de 1970, e parte dos anos 1980, vem acompanhado da expansão de atividades terciárias com fortes ligações aos movimentos de valorização de terras rurais, industriais e urbanas. A construção civil e a urbanização comercial, advindas dos investimentos governamentais que facilitavam o acesso às cidades do interior, trouxeram novas mudanças no cenário urbano e no cenário econômico para o município de Feira de Santana, como a construção de um anel rodoviário e o surgimento de novos conjuntos habitacionais populares que atendiam tanto aos interesses especulativos do capital imobiliário, quanto aos interesses comerciais e industriais em escoar e regionalizar os processos produtivos, tendo novamente o Estado um papel importante na transformação econômica social de Feira de Santana.

Dessa forma, o surgimento do CIS, enquanto motor de novos processos produtivos - seja com as economias de escala de novos produtos, seja quanto à atração de novas empresas de variados setores - acaba por incitar, segundo Góes Filho (2001), novas formas de cooperação para os processos produtivos, assim como novos arranjos locais com as indústrias instaladas e novos arranjos sociais (em termos econômicos, com o crescimento da classe industriaria na cidade). Também estão nesse processo novas alianças políticas entre os governos municipal e estadual com a classe industrial, ampliando, de forma significativa, o poder de articulação da região de Feira de Santana e, por conseguinte, a capacidade de partilha dos investimentos públicos.

Em face do exposto, o presente artigo tem como objetivo compreender como o processo de industrialização da economia baiana impactou demograficamente e ocupacionalmente o município de Feira de Santana. Metodologicamente, para atender ao objetivo proposto, foi levantada uma revisão teórica sobre o processo de industrialização da Bahia e do município de Feira de Santana, de modo a ressaltar o desenvolvimento de sua formação histórico-econômica desde o início da fixação populacional no século XVIII, através da criação da feira de gado, até a instalação do Centro Industrial do Subaé (CIS) em 1970. Essa análise teórica/histórica possibilita fornecer elementos qualitativos (explora informações mais subjetivas e em profundidade) para a análise quantitativa (aquela que se dá na coleta de dados estatísticos para testar uma hipótese).

A base de dados utilizada para embasar as discussões e os resultados da pesquisa corresponde às informações encontradas nos censos populacionais do Instituto Brasileiro de Geografia e Estatística (IBGE) nos anos que os censos foram realizados.

Este artigo compõe-se, além dessa introdução e das considerações finais, dos eixos: i) formação histórica e econômica do município de Feira de Santana e ii) as mudanças demográficas e ocupacionais em Feira de Santana após o processo de industrialização e de instalação do CIS.

\section{FORMAÇÃO HISTÓRICA-ECONÔMICA DO MUNÍCIPIO DE FEIRA DE SANTANA}

No século XVIII, em uma região localizada entre o litoral úmido e o interior do semiárido do estado da Bahia, através de uma fazenda denominada "Sant'Ana dos Olhos d'Água", de propriedade do casal Domingos Barbosa de Araújo e Ana Brandôa, dá-se início a fixação humana que iria resultar na criação da cidade de Feira de Santana. Segundo Santo (2003), após a criação de uma capela 
dedicada a Santa Ana e a São Domingos, a mesma logo se tornou um ponto de parada de descanso e hidratação para toda a espécie de viajante, sobretudo os boiadeiros e tropeiros em viagem de ida ou vinda para o sertão.

Em virtude desse fluxo populacional, em um curto espaço de tempo, algumas pessoas começaram a se fixar ao redor da região da fazenda, de modo que um pequeno comércio de alguns produtos essenciais para a subsistência dos moradores foi estabelecido por elas. A partir do trânsito de vaqueiros na região, logo surgiu também uma feira destinada ao comércio de gado da região Segundo Pedreira (1983, p. 15),

por volta de 1825 já existia no referido local, o Arraial de Sant'Ana dos Olhos D'Água, onde as terças-feiras de cada semana se ajuntam de 3 a 4 mil pessoas, e onde havia uma grande feira de gado. Esta feira era justificada em virtude da localização privilegiada do Arraial entre o Recôncavo e o Médio São Francisco, e das condições naturais ali encontradas (abundância de pastagens naturais e de água)

Assim, observa-se que bastou apenas um século para que Feira de Santana passasse de uma simples aldeia (pequeno povoado rural) para a localidade com a mais importante feira da Bahia. Essa feira era a base de sua economia e tornou-se, ao longo do tempo, um espaço ou um ambiente consubstanciado para além dos negócios, um verdadeiro espaço de encontro entre ciências, saberes e sabores, conforme discute Lima (2017).

A agricultura existia em função da demanda dos comerciantes e da subsistência dos moradores, sendo caracterizada pela grande produção de alimentos. Só mais tarde apareceu timidamente a plantação de fumo e de algodão. Vale ressaltar que os fardos de fumo e de algodão eram envoltos em couro, o que caracterizava a abundância da economia pecuarista local (SANTO, 2003).

A vila de Feira de Santana começa a se inserir nos processos de articulação, desconcentração e interiorização produtiva a partir de 1860. Com o aumento dos fluxos comerciais e do crescimento da feira de gado, o governo da Província da Bahia percebeu que as estradas que interligavam o interior do estado à capital Salvador encontravam-se em estado precário, fazendo com que o escoamento da produção ocorresse em vários dias de viagens por depender de transportes rudimentares como carros de bois e o lombo de animais. Nesta perspectiva, já em 1917, no governo de Antônio Sodré Aragão, foi traçado o primeiro plano de construção de estradas tendo o trecho Salvador-Feira de Santana (desde 1873 já considerada como cidade), como o principal foco, sendo que em 1938, segundo Cruz (1999, p. 177), o "município já experimentava o fortalecimento de sua posição como foco de irradiação e convergência de um sistema de rodovias, com recursos públicos da Bahia e da União".

O município seria beneficiário, assim, da confluência de interesses que reforçavam sua posição estratégica, perante os fluxos de capitais com destino ao Nordeste e a Salvador, fortalecendo o comércio local e gerando investimentos em atividades diversificadas. Desde cedo, os excedentes obtidos com a atividade comercial haviam proporcionado o surgimento de uma incipiente indústria beneficiadora do fumo e do preparo de carnes, couros e peles, cujo valor de produção era sobrepujado pela pecuária ou mesmo pela agricultura.

Desde 1860, aliás, registrava-se a presença de unidades de pequeno porte, baseadas em trabalhos manuais, com pouca utilização de vapor ou de máquinas. Em 1940, Feira de Santana já possuía 29 estabelecimentos, entre usinas de beneficiamento e fábricas de pequeno porte (CRUZ, 1999).

A migração do campo para a cidade com a sobreposição da atividade industrial/mercantil sobre a agrária segundo Brito (2009) se dá a partir do momento em que os migrantes entendem que é nas grandes cidades industriais/mercantis que se encontram as melhores oportunidades para uma ascensão social e uma melhoria no padrão de vida, fugindo da fome, da miséria, da escravidão por dívidas, do poder político e econômico exercido pelos latifundiários, da seca e da violência no campo. Já para Card e Peri (2016, p. 1336):

[...] os imigrantes e nativos podem ser classificados em um número relativamente pequeno de grupos de habilidades e em seguida modelam a imigração como uma alteração na oferta de diferentes tipos de trabalho.

Estabelecidos estes condicionantes, a Figura 1 demonstra a evolução territorial do município de Feira de Santana e região de 1827 até 1970 conforme os fluxos migratórios foram acontecendo na referida região. 
Figura 1 - Feira de Santana: Evolução Territorial regional,1827-1920.

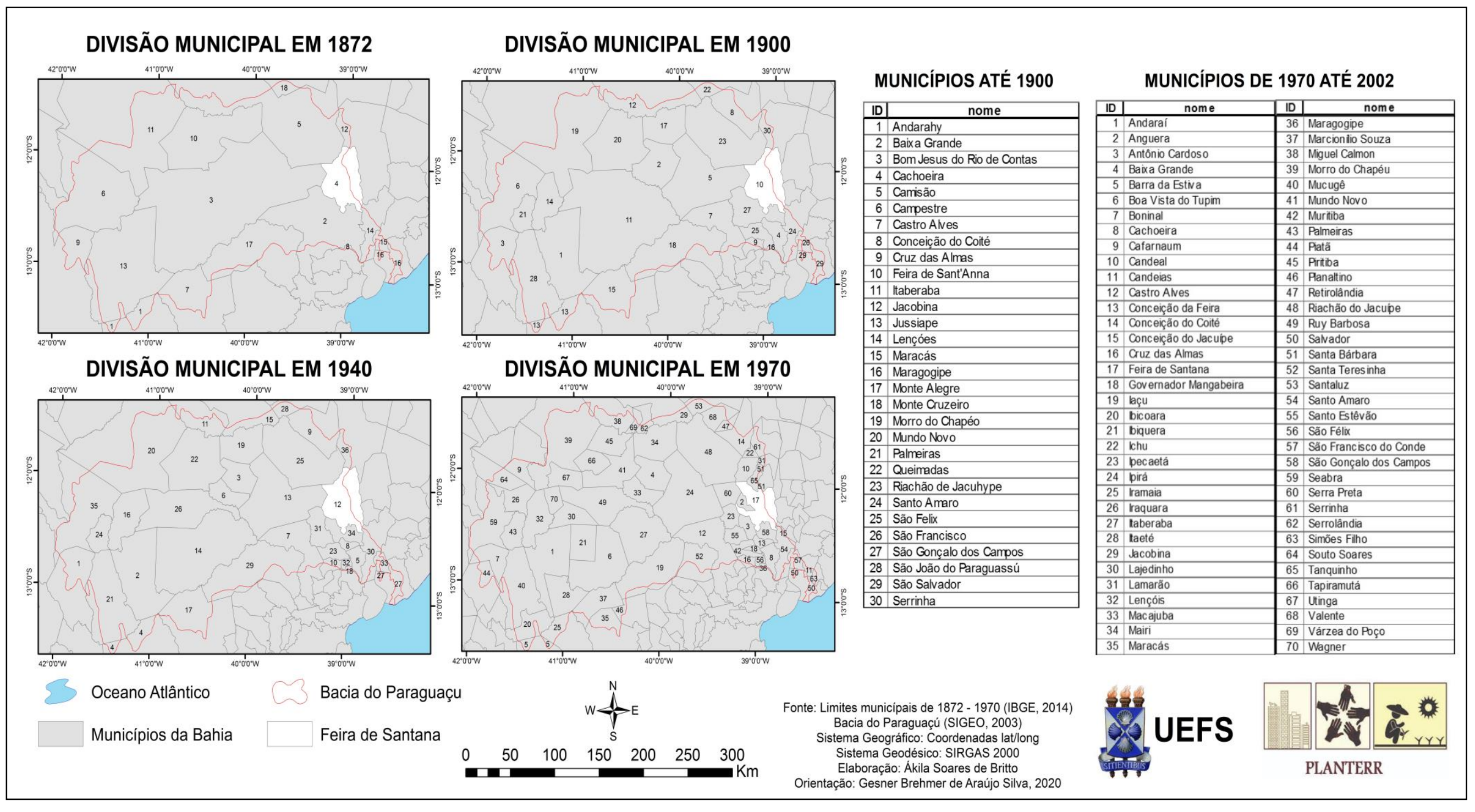


Esta "indústria nascente" feirense dos anos 1940 enfrenta dois problemas limitantes ao seu desenvolvimento no município como principal atividade econômica: o primeiro diz respeito ao próprio tamanho do mercado consumidor local e regional, ainda marcados por baixos níveis de renda; e em segundo e mais importante, a concorrência maciça de produtos mais industrializados advindos de Salvador. Estabelecida esta conjuntura, a indústria local feirense, num primeiro momento, foca sua produção para o mercado local e regional em produtos agrícolas de baixo valor agregado já de forte presença local (fumo, algodão e peles) e produtos complementares em relação à produção das cidades vizinhas. Esse foco é mantido na década seguinte e, graças ao mercado local, Feira de Santana experimenta um grande crescimento industrial durante as décadas de 1940 e 1950.

A partir dos anos de 1960, com o crescimento urbano e industrial de Salvador através dos processos de industrialização já explicitados na introdução deste trabalho, onde segundo Freitas (1996) e Cruz (1999), a capital do estado integra-se produtivamente à lógica do capital industrial nacional. Feira de Santana começa de fato a mudar sua estrutura e sua relação campo-cidade, quando passa a atuar como um centro de serviços de apoio a transportes de passageiros, reforçando ainda mais o seu papel histórico de entroncamento comercial, fazendo parte agora também da cadeia produtiva desse capital mercantil e industrial. Observa-se em que pese a pressão industrial pela urbanização como algo superior no processo econômico uma relação ainda dialógica entre as dimensões campo-cidade neste município.

Com o advento dessas mudanças, e a consequente implantação do CIS, a atividade industrial de Feira de Santana se concentra e se organiza, uma vez que antes era dispersa e desorganizada, espalhada pela malha urbana do município sem qualquer tipo de conexão entre elas. No que diz respeito à estrutura fundiária, Araújo (2015, p. 19) destaca que:

O município possui, como a maioria dos demais municípios baianos, uma estrutura fundiária concentrada, prevalecendo pequenas propriedades rurais, numa mini fundiarização promovida, em especial pela dinâmica municipal de sua relação campo cidade, pois o município possui uma política de crescimento e desenvolvimento urbano, a qual o espaço rural não está contemplado. A mini fundiarização garante a manutenção constante da oferta de terras para lotes urbanos.

Uma característica observada por Araújo (2015) e Freitas (2014) é que essas pequenas propriedades rurais de Feira de Santana obedecem à mesma lógica de outros municípios baianos: proprietários com um grande número de herdeiros, o que "força" aqueles que não herdarão a terra a trabalharem muito cedo, ajudando seus pais ou na maioria dos casos, buscando sustento e moradia nas cidades próximas, fazendo, com efeito, uma articulação forçada ou "naturalizada" entre as dimensões urbanas e rurais, sem perceber a imposição do sistema econômico industrial.

Nesse contexto, iniciam-se assim as relações de trabalho que vão desde o "meeiro" até o arrendamento de terras, passando pelo trabalho em atividades não agrícolas e no emprego ou subemprego quase sempre na cidade ou no povoado mais próximo de sua propriedade (trabalho acessório), distribuindo-se da seguinte forma: conforme o sexo, a idade e a escolaridade; primeiro dos jovens, não deixando também, de acontecer com os pais - para as meninas, as mais diversas atividades domésticas na casa de terceiros, e no comércio local; para os meninos atividades de auxiliar das mais diversas profissões, principalmente na construção civil e nas oficinas de automóveis em ambas as situações, o peso da falta de escolaridade e qualificação profissional são os maiores entraves (ARAÚJO, 2015).

Com o decorrer do tempo observa-se que o processo de fragmentação das pequenas propriedades rurais vem acelerando e se mantendo, principalmente com a disponibilidade de novos elementos que antes não faziam parte do cotidiano das famílias de pequenos produtores, como a energia elétrica e água encanada, o sistema de telefonia e internet, o posto médico, pequenos comércios diversos, serviços de estética e beleza e, em alguns casos, a coleta de lixo, a escola primária e de ensino médio, o transporte público coletivo - dos mais diversos e a todo instante, e mais ainda a revolução urbana da motocicleta (ARAÚJO, 2015). 
Estes novos processos dentro do espaço rural, aliados ao crescimento das cidades e ao nascimento do distrito industrial do Subaé, colabora para que as relações econômicas entre os setores mudem de forma consistente, com uma predominância dos setores industriais e terciários sobre o primário. Nesse sentido, a próxima seção desse artigo pretendeu analisar essas novas relações econômicas, demográficas e ocupacionais impactadas pelo processo de industrialização da Bahia.

\section{AS MUDANÇAS DEMOGRÁFICAS E OCUPACIONAIS EM FEIRA DE SANTANA APÓS O PROCESSO DE INDUSTRIALIZAÇÃO E INSTALAÇÃO DO CIS}

A proposta da última seção do artigo foi analisar as mudanças demográficas e ocupacionais no município de Feira de Santana após o processo de industrialização da economia baiana e da instalação do Centro Industrial do Subaé.

Hoje, nas relações econômicas, o urbano-industrial tem se mostrado o elemento dominante subordinando o campo à cidade, situação que emerge como uma característica recente a partir do advento da industrialização, que por sua vez se mostra como um fenômeno de escala mundial que se intensifica no Brasil nos decênios de 1960 e 1970. Porém, a modernização não ficou restrita à cidade e à indústria uma vez que, ao ser traçado o quadro de mudanças econômicas de nossa história recente, observa-se que o campo não ficou banido do contexto de mudanças produtivas. O espaço rural, subordinado ao capital e aos interesses urbanos, tem sua produção orientada para atender às necessidades diretas e indiretas da cidade (ARAÚJO, 2015).

Essa sobreposição do urbano-industrial em relação ao campo se dá no município de Feira de Santana na questão da demografia de acordo com os dados disponíveis no Censo Demográfico do IBGE (Instituto Brasileiro de Geografia e Estatística) e que estão disponíveis na Tabela 1. O os dados demonstram que houve um aumento considerável da população do município após 1950 (início do processo de industrialização baiana), com taxa de crescimento populacionais médias de $32,18 \%$ nas seis décadas seguintes, com destaque para a década de 1980(com a consolidação da instalação do Centro Industrial do Subáe) , com crescimento de 53,36\%.

Tabela 1 - Feira de Santana: Crescimento Demográfico entre 1872 e 2010.

\begin{tabular}{ccc}
\hline Ano Base & $\begin{array}{c}\text { População Total de Feira de } \\
\text { Santana }\end{array}$ & $\begin{array}{c}\text { Taxa de Crescimento } \\
\text { Populacional (em \%) entre o ano } \\
\text { base do levantamento anterior e } \\
\text { o seguinte }\end{array}$ \\
\hline $\mathbf{1 8 7 2}$ & 32.955 & - \\
\hline $\mathbf{1 8 9 0}$ & 38.621 & 17,19 \\
\hline $\mathbf{1 9 0 0}$ & 61.758 & 59,91 \\
\hline $\mathbf{1 9 2 0}$ & 77.600 & 25,65 \\
\hline $\mathbf{1 9 4 0}$ & 83.268 & 7,30 \\
\hline $\mathbf{1 9 5 0}$ & 107.205 & 28,74 \\
\hline $\mathbf{1 9 6 0}$ & 141.757 & 32,22 \\
\hline $\mathbf{1 9 7 0}$ & 190.076 & 34,08 \\
\hline $\mathbf{1 9 8 0}$ & 291.504 & 53,36 \\
\hline $\mathbf{1 9 9 0}$ & 406.447 & 39,43 \\
\hline $\mathbf{2 0 1 0}$ & 481.137 & 18,37 \\
\hline Fonte IBGE (1872,1890,1900,1920,1940,1950,1960,1970,1980,1990,2000,2010).
\end{tabular}


É importante destacar algumas questões a respeito da dinâmica demográfica do referido município e seus desmembramentos ocorridos principalmente nos municípios circunvizinhos, tais como Tanquinho, Irará, Santa Bárbara entre outros, que foram emancipados entre as décadas de 1950 e 1960, cujo processo de emancipação afetou a dinâmica demográfica da região no sentido de que o crescimento populacional seria ainda mais intenso em Feira de Santana caso se incluíssem as populações que foram classificadas como residentes no novo município.

Ao ser analisada a composição da população do município de Feira de Santana (aqui embasada pelos locais de residência) nos referidos anos, também é possível notar a mudança de perfil da população do rural para o urbano, conforme poderemos observar na tabela 2 abaixo.

Conforme os dados dos Censos do IBGE supramencionados, entre 1940 e 2010 há uma mudança no perfil da população feirense. Até os anos 1960, a população do município era composta majoritariamente pela parcela correspondente da população rural. Após os anos 1970 (com a instalação do CIS e os processos de integração produtiva por parte do governo nacional e estadual), a população urbana passa a responder de forma majoritária na composição populacional. Os desmembramentos municipais também afetam o grau de urbanização dos municípios-mãe (de onde surgem os novos filhos), uma vez que geralmente as áreas cedidas aos novos municípios são compostas por vilas urbanas cercadas por núcleos de assentamento rurais. Assim, o município-mãe tende aparecer no censo seguinte como mais urbanizado do que antes devido a essa perda de população para o município-filho.

O aumento no grau de urbanização medido pelo percentual da população urbana pode indicar processo migratório quando aliado à variação do crescimento populacional. É o caso dos anos 1950 a 1960 quando a população cresceu $32 \%$ e o peso da população urbana cresceu de $50 \%$ para $70 \%$ e no período seguinte (60-70) com crescimento de $34 \%$ e salto do grau de urbanização de $70 \%$ para $80 \%$. Por outro lado, quando não há expressivo crescimento populacional municipal, o aumento no grau de urbanização pode estar mais associado à redistribuição da população internamente ao município (mobilidade residencial) ou expansão da mancha urbana, que ocasiona reclassificação de setores censitários. Os dados em relação à composição populacional do município de Feira de Santana também são apresentados na Tabela 2.

Tabela 2 - Feira de Santana: Composição da População em termos percentuais: 1940-2010.

\begin{tabular}{cccc}
\hline Anos & População Total & População Urbana (\%) & População Rural (\%) \\
\hline $\mathbf{1 9 4 0}$ & 83.268 & 23,62 & 76,38 \\
\hline $\mathbf{1 9 5 0}$ & 107.205 & 31,97 & 68,03 \\
\hline $\mathbf{1 9 6 0}$ & 141.757 & 49,29 & 50,71 \\
\hline $\mathbf{1 9 7 0}$ & 190.076 & 70,63 & 29,37 \\
\hline $\mathbf{1 9 8 0}$ & 291.504 & 80,24 & 19,76 \\
\hline $\mathbf{1 9 9 0}$ & 406.447 & 85,86 & 14,14 \\
\hline $\mathbf{2 0 1 0}$ & 481.137 & 89,68 & 10,32 \\
\hline & 556.462 & 91,76 & 8,24 \\
\hline
\end{tabular}


Com base nos dados da tabela 2, percebe-se que até 1950 a população do município de Feira de Santana era majoritariamente rural (68,03\%). Os estudos de Araújo (2015), Guerra e Teixeira (2002) e Cavalcante (2008), afirmam que a partir de 1950, tanto no estado como no país, é observado o início de processos intensos de crescimento (dirigido por agentes econômicos, com destaque para o papel do Estado, através de ofertas de terrenos dotados de infraestrutura e incentivos fiscais e do capital financeiro internacional), de urbanização e modernização das atividades produtivas (principalmente a indústria), o que resultou em um crescimento econômico mais acelerado.

Em termos ocupacionais, os dados demonstram que em 1970 ainda predominava no município as atividades ligadas ao setor primário que empregava $54,31 \%$ do total da população ocupada, enquanto a indústria correspondia por $26,40 \%$. Essa situação é rapidamente modificada já em 1980 , com o crescimento do setor terciário que passa a corresponder a quase $61 \%$ da população ocupada, enquanto a indústria passa a responder por $15,1 \%$. Os dados estão disponíveis na tabela 3 . É importante destacar que estes dados do IBGE $(1970,1980,1990,2000,2010)$ não especificam a ocupação formal ou informal, mas sim os setores que mais ocupam força de trabalho no referido município.

Tabela 3 - População ocupada em Feira de Santana por década e percentual,1970-2010.

\begin{tabular}{ccccc}
\hline Período/Setor & Primário & Indústria & Construção Civil & Terciário \\
\hline $\mathbf{1 9 7 0}$ & 54,31 & 26,4 & - & \\
\hline $\mathbf{1 9 8 0}$ & 15,47 & 15,1 & 8,94 & 60,48 \\
\hline $\mathbf{1 9 9 0}$ & 10,2 & 13,57 & 8,47 & 67,76 \\
\hline $\mathbf{2 0 0 0}$ & 8,87 & 13,52 & 7,11 & 70,49 \\
\hline $\mathbf{2 0 1 0}$ & 7,28 & 12,73 & 8,94 & 71,05 \\
\hline
\end{tabular}

Fonte - IBGE (1970,1980,1990,2000,2010).

Uma análise complementar do emprego formal se dá nos dados da tabela 4, ao analisarmos os dados da composição do mercado de trabalho de Feira de Santana em comparativo com a Bahia segundo os dois últimos censos demográficos. Isso permite uma análise desagregada dos dados ocupacionais, principalmente em relação aos ocupados formais, aos desocupados e informais.

Feira de Santana se encontrava em 2000, com uma população economicamente ativa (PEA) de 228.681 mil pessoas, das quais 118.500 se encontravam empregadas e com grau de informalidade de $60,51 \%$. No comparativo com o censo de 2010 , percebe-se que há um recuo nos graus de informalidade tanto da Bahia quanto em Feira de Santana (60,51 \% para 52,97\%), porém ainda demonstrando que mais da metade da população da PEA se encontrava (sobre)vivendo no mercado informal.

É importante destacar que, nesse artigo, para se encontrar o número de pessoas presentes no mercado informal da Tabela 4, foi utilizado o critério de somar as pessoas ocupadas sem carteira assinada com as pessoas que trabalham por conta própria e os trabalhadores auxiliares familiares. Já o grau de informalidade é encontrado pela razão entre os trabalhadores em situação informal e a população ocupada total. 
Tabela 4 - Indicadores do mercado de trabalho da Bahia e Feira de Santana, 2000-2010.

\begin{tabular}{|c|c|c|c|c|}
\hline \multirow[b]{2}{*}{ População } & \multicolumn{2}{|r|}{2000} & \multicolumn{2}{|c|}{2010} \\
\hline & Bahia & Feira de Santana & Bahia & $\begin{array}{l}\text { Feira de } \\
\text { Santana }\end{array}$ \\
\hline Total & 13.070 .250 & 480.949 & 14.016.906 & 556.642 \\
\hline PIA $^{4}$ & 10.389 .119 & 386.212 & 11.764.109 & 471.446 \\
\hline PEA $^{5}$ & 5.613 .079 & 228.681 & 6.555 .397 & 292.296 \\
\hline Ocupados & 4.581 .594 & 186.795 & 5.841 .078 & 261.614 \\
\hline Empregado & 2.768 .381 & 118.500 & 3.753 .831 & 178.569 \\
\hline \multicolumn{5}{|l|}{ Com Carteira } \\
\hline Assinada & 1.167 .720 & 58.473 & 1.906 .421 & 105.645 \\
\hline \multicolumn{5}{|l|}{$\begin{array}{c}\text { Militares e } \\
\text { Funcionalismo } \\
\text { Público }\end{array}$} \\
\hline Estatutário & 200.974 & 7.975 & 244.835 & 11.938 \\
\hline \multicolumn{5}{|l|}{ Sem carteira } \\
\hline Assinada & 1.399 .687 & 52.052 & 1.602 .574 & 60.986 \\
\hline \multicolumn{5}{|l|}{$\begin{array}{l}\text { Não remunerado } \\
\text { em ajuda a } \\
\text { membro do }\end{array}$} \\
\hline $\begin{array}{l}\text { Trabalhador na } \\
\text { produção para } \\
\text { próprio consumo }\end{array}$ & 306.796 & 6.927 & 544.022 & 10.046 \\
\hline Empregador & 96.703 & 7.313 & 80.841 & 5.457 \\
\hline Conta Própria & 1.143 .388 & 50.188 & 1.321 .367 & 62.574 \\
\hline Desocupados & 1.031 .485 & 41.886 & 714.319 & 30.682 \\
\hline $\begin{array}{l}\text { Não- } \\
\text { economicamente } \\
\text { ativa }\end{array}$ & 4.776 .040 & 157.531 & 5.208 .712 & 179.150 \\
\hline Informalidade & 3.116 .196 & 113.034 & 3.608 .980 & 138.574 \\
\hline $\begin{array}{c}\text { Grau de } \\
\text { Informalidade }\end{array}$ & $68,02 \%$ & 60,51 & 61,79 & 52,97 \\
\hline
\end{tabular}

Fonte - IBGE- Censo Demográfico (2000, 2010) Tabela 2031.

${ }^{4}$ População em idade ativa.

${ }^{5}$ População economicamente ativa.

Caminhos de Geografia 
A análise dos dados do IBGE demonstra que, de fato, após o início do processo de industrialização da economia baiana que promove mudanças significativas tanto na estrutura produtiva, quanto na estrutura urbana dos municípios, há uma inversão sob a ótica demográfica no município de Feira de Santana, que passa a ter, a partir dos anos 1970, uma população majoritariamente urbana. Porém, em análise conjunta aos dados ocupacionais, percebe-se que o maior crescimento em termos empregatícios resulta do setor terciário, que por sua vez compreende as áreas de comércio e de serviços.

Em face do exposto, os dados disponibilizados pelo IBGE corroboram com as teses de Carvalho Júnior et al. (2002), Cruz (1999) e Almeida (2009), de que a partir da década de 1970 do século XX, com a tentativa, por parte do governo baiano, de dinamizar a produção do estado via industrialização das cidades do interior, aliada ao caso específico do município com a implantação e instalação do CIS (Centro Industrial do Subaé), há uma migração das áreas rurais para a área urbana não apenas em busca de melhores condições de trabalho, mas também pela fuga de problemas comuns na área rural tais como a miséria da fome, da escravidão por dívidas, da opressão dos latifundiários, da seca e da violência no campo. Essa dinâmica migratória provocou (e provoca) mudanças de ordem social, econômica e urbana, como destaca Araújo (2015), com o surgimento dos assentamentos subnormais (favelas) e a criação de novos conjuntos habitacionais para acolher os novos trabalhadores, expandindo a malha urbana do município cada vez mais em direção ao externo de seu anel viário. Ao mesmo tempo, provoca mudanças como o inchaço do setor terciário da economia e o aumento da informalidade, que passa a abrigar com remunerações baixíssimas aqueles que não conseguem emprego no Centro Industrial do Subaé.

\section{CONSIDERAÇÕES FINAIS}

A interpretação sobre as implicações do processo de industrialização na economia permite considerar processos que estão de algum modo interligados, desde as articulações produtivas da economia global, passando pela atuação do estado como formulador de políticas voltadas ao desenvolvimento e urbanização em diferentes unidades territoriais do estado. Portanto, parece crível analisar as implicações da industrialização baiana no município de Feira de Santana em uma série temporal distinta em termos conjunturais e sociais sobre uma variável tão importante quanto a variável demográfica.

Dentro desta perspectiva, o presente artigo teve como principal objetivo analisar como o processo de industrialização baiano, iniciado formalmente na década de 50 no século passado influenciou no processo de industrialização e urbanização da cidade de Feira de Santana, que tem como marco a implementação e instalação do CIS (Centro Industrial do Subaé) nos anos 70. Neste contexto, inferiuse que a partir dos anos 50 há uma transformação na composição da população do município de Feira de Santana, antes hegemonicamente rural, para a hegemonia urbana, acompanhando o processo de urbanização e industrialização brasileiro, contudo que a maior parte da população ocupada não se destinou ao setor industrial (naquela época fortemente estimulado pelos governos nacionais e estadual) e sim ao setor terciário e a informalidade.

Com efeito, uma análise mais detalhada da composição educacional da população ocupada em Feira de Santana na série temporal observada, poderia contribuir para chegar ao entendimento de porque mesmo com o estímulo da política industrial nacional e estadual, a dinâmica populacional voltou-se aos setores de menor remuneração e menor grau de instrução. Apenas o estímulo por parte do estado na industrialização e urbanização não parece ser suficiente para promover a dominância do setor industrial na ocupação econômica do município, somente para que a população urbana crescesse em taxas significativas maiores que a população rural.

Dentre as causas desta nova hegemonia urbana, podemos destacar os processos de modernização produtiva, a expansão da malha urbana do município, principalmente fora do anel viário, com a criação de novos conjuntos habitacionais (criação e ampliação do mercado imobiliário no contexto industrial), bem como o surgimento de favelas para agrupar esta nova conjuntura demográfica da cidade e que certamente podem ser melhor exploradas em futuras publicações. 


\section{REFERÊNCIAS}

ALMEIDA, Janeide Oliveira da Silva. A implantação do Centro Industrial do Subaé em Feira de Santana - Bahia através de uma industrialização planejada. In: ENCONTRO DE GEÓGRAFOS DA AMÉRICA LATINA, 12, 2009, Montevidéu. Anais [...]. Montevidéu: EasyPlanners, 2009.

ARAÚJO, Wodis Kleber Oliveira. A relação campo-cidade no município de Feira de SantanaBA:Renda da terra, campesinato e ruralidades. Tese (Doutorado em Geografia) Pós Graduação em Geografia, Universidade Federal de Sergipe, São Cristovão, 2015.

BRITO, Fausto. As migrações internas no Brasil: um ensaio sobre os desafios teóricos recentes. Belo Horizonte: UFMG/Cedeplar. 20p. (Texto para discussão; 366), 2009. Disponível em : https://www.cedeplar.ufmg.br/publicacoes/textos-para-discussao/textos/2009/629-366-as-migracoesinternas-no-brasil-um-ensaio-sobre-os-desafios-teoricos-recentes .Acesso em: 21 ago. 2019.

CARD, David; PERI, Giovanni. Immigration Economics by George J. Borjas: A Review Essay. Journal of Economic Literature, v. 54, n. 4, pp. 1333-1349, dez. 2016. https://doi.org/10.1257/jel.20151248

CAVALCANTE, Luiz Ricardo. Maturidade tecnológica e intensidade em pesquisa e desenvolvimento: o caso da indústria petroquímica no Brasil. Revista Organizações \& Sociedade, Salvador, v. 5, pp. 121-143, 2008. https://doi.org/10.1590/S1984-92301998000200006

CARVALHO JÚNIOR, César Vaz de; PESSOTI, Gustavo Casseb; PEREIRA, Ítalo Guamais Aguiar. Panorama da economia baiana sob a ótica do PIB 1975/2000: dez anos de economia baiana. Revista Bahia Análise \& Dados, Salvador, v. 16, pp. 413-430, 2002.

CRUZ, Rossine Cerqueira da. A inserção de Feira de Santana (BA) nos processos de integração produtiva e de desconcentração econômica nacional. Tese (Doutorado em Economia) Instituto de Economia, Universidade Estadual de Campinas, Campinas, 1999.

FREITAS, Nacelice Barbosa. Urbanização em Feira de Santana: influência da industrialização: 1970-1996. Dissertação (Mestrado em Arquitetura e Urbanismo) Faculdade de Arquitetura, Universidade Federal da Bahia, Salvador, 1996.

FREITAS, Nacelice Barbosa. $O$ descoroamento da princesa do sertão: De "chão" a território, o "vazio" no processo da valorização do espaço. Tese (Doutorado em Geografia) Pós Graduação em Geografia, Universidade Federal de Sergipe, São Cristóvão, 2014.

GÓES FILHO, Edelvino da Silva. Condições da industrialização em Feira de Santana (19691989). Dissertação (Mestrado em Economia) - Faculdade de Economia, Universidade Federal da Bahia, Salvador, 2001.

GUERRA, Oswaldo; TEIXEIRA, Francisco. Estratégias para o desenvolvimento da indústria na Região Metropolitana de Salvador. Revista Bahia Século XXI, Salvador, v. 1, pp. 147-204, 2000.

GUERRA, Oswaldo; GONZALES, Paulo. Novas mudanças estruturais na economia baiana: mito ou realidade. Fortaleza: Revista Econômica do Nordeste, Fortaleza, v. 32, pp. 308-321, 2000.

GUERRA, Oswaldo; TEIXEIRA, Francisco. 50 anos da industrialização baiana: do enigma a uma dinâmica exógena e espasmódica. Revista Bahia: Análise \& Dados, Salvador, v. 10, pp. 87-98, 2002.

IBGE - Instituto Brasileiro de Geografia e Estatística. Censo Demográfico: população e habitação,1940. Parte XII,tomo I, série regional.Rio de Janeiro: IBGE ,1950.

Censo Demográfico:Estado da Bahia, 1950. V. XX, tomo I.Rio de Janeiro: IBGE ,1955.

Sinopse Preliminar do Censo Demográfico: Brasil.1960.Rio de Janeiro: IBGE,1960.

Censo Demográfico Bahia: recenseamento geral,1970, v.1, tomo XIII. Rio de Janeiro: IBGE,1973. $\overline{\text { IBGE,1983. }}$

Censo Demográfico 1980: dados distritais - Bahia, v.1, tomo 3, n.13. Rio de Janeiro:

Censo Demográfico 1991: resultados do universo relativos às características da população e dos domicílios, n.17 - Bahia. Rio de Janeiro: IBGE, 1991.

Sinopse preliminar do Censo Demográfico da Bahia. Rio de Janeiro: IBGE, 2000. 
Sinopse preliminar do Censo Demográfico da Bahia. Rio de Janeiro: IBGE, 2010.

LIMA, José Raimundo de Oliveira. Economia Popular e Solidária e Desenvolvimento Local: uma relação estratégica. Feira de Santana-BA: Novas Edições Acadêmicas, 2017.

MASCARENHAS, Albérico Machado. A atividade de fomento na Bahia: uma retrospectiva dos últimos 50 anos. Reflexões de economistas baianos, Salvador, v. 1, pp. 62-77, 2001.

NÓVOA, Jorge Luiz Bezerra. Raizes da dependência econômica da Bahia. Dissertação (Mestrado em Economia) Faculdade de Economia, Universidade Federal da Bahia, Salvador, 1979.

PEDREIRA, Pedro Torres. Município de Feira de Santana: das origens às instalações. Salvador: Gráfica e Editora LTDA, 1983.

PESSOTI, Gustavo Casseb. Um Estudo da Política Industrial na Bahia entre 1950 e 2005. Dissertação (Mestrado em Desenvolvimento Regional e Urbano) PPDRU, Unifacs, Salvador, 2008.

PESSOTI, Bruno Casseb; PESSOTI, Gustavo Casseb. A economia baiana e o desenvolvimento industrial: Uma análise do período 1978-2010. RDE- Revista de Desenvolvimento Econômico, Salvador, v. 22, pp. 22-45, 2010.

SANTO, Sandra Medeiros. O desenvolvimento urbano em Feira de Santana. Revista Sitientibus, Feira de Santana, n. 28, pp. 9-20, 2003.

SEI - Superintendência de Estudos Econômicos e Sociais da Bahia. Evolução territorial e administrativa do Estado da Bahia: um breve histórico. Editora SEl. Salvador, 2000.

SOUTO, Roberto Lucas Spínola; PESSOTI, Fernanda Calasans Costa Lacerda; PESSOTI, Gustavo Casseb; SPINOLA, Noelio Dantaslé. Do Plano a realidade: Uma análise do Programa de Implantação dos distritos industriais no interior do estado da Bahia. In: ENCONTRO DE ECONOMIA BAIANA, 13, 2017, Salvador. Anais. Salvador. SEI, 2017.

Recebido em: 18/03/2021

Aceito para publicação em: 18/12/2020 